\title{
A organização do ensino em cursos de Pedagogia EAD
}

\author{
Márcia Guimarães Oliveira de Souza ${ }^{1}$ \\ marcia.guimaraes@uniube.br
}

\begin{abstract}
Marilene Ribeiro Resende ${ }^{2}$
\end{abstract}
marilene.resende@uniube.br

\section{Resumo}

O objetivo do estudo é investigar como o professor organiza o ensino na modalidade $\mathrm{EaD}$ com vistas à mediação didáticopedagógica, especialmente nos Ambientes Virtuais de Aprendizagem (AVA). Para a realização do estudo, foram inicialmente selecionadas duas Instituições de Ensino Superior (IES) que oferecem o curso de Pedagogia-EaD, situadas no Triângulo Mineiro, no Estado de Minas Gerais; uma IES pública e uma IES privada. Desenvolvido numa abordagem qualitativa, a partir de pesquisa bibliográfica, documental e de campo, usando, para a análise dos dados, a técnica de triangulação de fontes. A fundamentação teórica sobre a mediação e a atividade de ensino está apoiada em Vigotski e em seus parceiros, Luria e Leontiev, entre outros. Os resultados demonstraram que organização das atividades de ensino está submetida a determinações verticalizadas, que engessam e fragmentam a atuação docente, não dando ao professor oportunidade de realizar a mediação didático-pedagógica apropriadamente.

Palavras-Chave: educação a distância; formação de pedagogos; mediação didático-pedagógica; interação.

1 Mestre em Educação pela UNIUBE. Professora da UNIUBE, Uberaba/MG.

2 Doutora em Educação Matemática pela PUC/SP. 


\title{
The organization of teaching in Pedagogy courses in distance education
}

\begin{abstract}
The aim of this study is to investigate how the professor organizes the teaching in the Teaching at Distance Modality (TDM) focusing at the didactic pedagogical mediation, mainly in Virtual Learning Environment (VLE). In order to accomplish this study two High Education Institutions (HEI), which offer the course of Pedagogy (TDM), were initially selected; these institutions are located in Triangulo Mineiro, in the state of Minas Gerais, one of these institutions is public and the other is a private one. Developed in a qualitative approach, from a bibliographical, documental and field research using to the data analysis, the technique of triangulation. The theoretical framework about the mediation and the teaching activity is supported in Vigotski and in his partners Luria e Leontiev, among others. The results demonstrated that the organization of the teaching activities is submitted to the verticalized determinations that stiff and fragment the teachers acting, not giving the teacher the opportunity of accomplishing properly the didactic pedagogical mediation.
\end{abstract}

Keywords: education at distance; pedagogical formation; didaticpedagogical mediation; interaction.

\section{Introdução}

Nos últimos anos, vem ocorrendo um gradativo aumento na oferta de cursos a distância por universidades particulares e federais do País. Segundo dados do Brasil (2009), a matrícula em cursos na modalidade de ensino a distância (EaD) representa $14,6 \%$ do total de matrículas em cursos superiores. Entre eles, há uma parcela grande voltada para a formação de professores para atuarem, principalmente, no Ensino Básico - 45,8\% dos matriculados na EaD estão em cursos de licenciatura. A exigência da Lei de Diretrizes e Bases da Educação Nacional, Lei n. 9.394, de 1996, também provocou o aumento da procura por cursos nessa modalidade, uma vez que atraiu professores em serviço que necessitavam 
dessa adequação. O momento histórico atual, a globalização, o desenvolvimento tecnológico, também contribuíram para o aumento da oferta de cursos para a formação de professores nessa modalidade. Mas de que forma o processo ensino-aprendizagem se efetiva na EaD?

Para verificarmos o que tem sido produzido sobre a formação do pedagogo nessa modalidade, fizemos uma busca no Banco de Teses da CAPES, em meados de 2012. Utilizamos o descritor "formação em Pedagogia a distância", encontramos um trabalho, em nível de mestrado, e nenhum em nível de doutorado. Fica evidente que o tema escolhido para esta pesquisa carece de trabalhos investigativos.

Nos Referenciais de Qualidade para a Educação Superior a Distância, o MEC e a extinta Secretaria de Educação a Distância não determinam um padrão de organização para os cursos a distância das instituições brasileiras:

Não há um modelo único de educação a distância! Os programas podem apresentar diferentes desenhos e múltiplas combinações de linguagens e recursos educacionais e tecnológicos. A natureza do curso e as reais condições do cotidiano e necessidades dos alunos são os elementos que irão definir a melhor tecnologia e metodologia a ser utilizada, bem como a definição dos momentos presenciais necessários e obrigatórios, para estágios supervisionados, práticas em laboratórios de ensino, tutorias presenciais nos polos descentralizados de apoio presencial e outras estratégias. Apesar da possibilidade de diferentes modos de organização, um ponto deve ser comum a todos aqueles que desenvolvem projetos nessa modalidade: é a compreensão de EDUCAÇÃO como fundamento primeiro, antes de se pensar no modo de organização: A DISTÂNCIA. (BRASIL, 2007, p. 7)

No trecho acima, fica claro que as questões educacionais devem ser prioritárias, independentemente da modalidade de ensino que as instituições adotem. Esse posicionamento do Ministério em não adotar um padrão é importante, pois um modelo único "engessaria" o trabalho desenvolvido pelas instituições e também não garantiria qualidade no ensino dos cursos oferecidos por elas. O Decreto n. 5.622/05, que regulamentou a educação a distância, ao defini-la, estabelece que a mediação didático-pedagógica nos processos de ensino e aprendizagem deve ocorrer por meio das tecnologias de informação e comunicação. Sendo assim, cabe perguntar: as TIC nas IES pesquisadas têm cumprido 
esse papel? Têm sido elas suficientes para garantir a mediação professorconteúdo-aluno? As instituições têm assumido esse compromisso, considerando os aspectos pedagógicos, de infraestrutura e de recursos humanos, condizentes com as propostas pedagógicas dos cursos? Essas são apenas algumas questões, entre outras, que poderíamos citar, e, a partir delas, o trabalho realizado pelos docentes se transformou para nós, em fonte de motivação e inspiração para a realização desta pesquisa.

Entre as várias possibilidades de aprofundamento sobre as questões relativas a essa modalidade de ensino e às implicações relacionadas ao trabalho desenvolvido pelo professor que nela atua, escolhemos uma que elegemos como um dos pontos fundamentais a serem considerados pelas IES - a mediação didático-pedagógica.

Para a teoria histórico-cultural, a mediação é fator essencial no processo ensino-aprendizagem, ao estabelecer a relação dialética entre conhecimento e desenvolvimento. Por considerarmos que as finalidades do ensino a distância não podem ser diferentes das finalidades do ensino presencial, esta pesquisa buscou investigar essa mediação didáticopedagógica em cursos de Pedagogia-EaD, a partir da abordagem histórico-cultural.

Decidimos focar no ensino, no trabalho desenvolvido pelo professor que atua na EaD, pois trabalhar nessa modalidade implica em organização, instrumentos de trabalho, entre outros fatores diferentes do ensino presencial, devendo, contudo, visar a mesma qualidade na formação.

$\mathrm{Na}$ abordagem histórico-cultural, o professor é o organizador do ensino; então, a nossa pesquisa tem o objetivo de analisar como o professor organiza o ensino nos cursos de Pedagogia-EaD em duas IES na Região do Triângulo Mineiro, com vistas à mediação didático-pedagógica. As IES pesquisadas são: uma de natureza institucional particular e a outra pública, sendo identificadas na pesquisa por instituições " $A$ " e " $\mathrm{B}$ ", respectivamente. A IES particular foi escolhida porque é pioneira na oferta de EaD na região, estando presente nas cinco regiões do País. A IES pública oferta o curso de Pedagogia pela Universidade Aberta do Brasil (UAB) na Região do Triângulo Mineiro. Segundo dados colhidos no site da CAPES/UAB, a UAB é uma iniciativa do governo federal que 
consiste em uma rede nacional experimental voltada para a pesquisa de novas metodologias de ensino para a educação superior, com a finalidade de expandir, democratizar e interiorizar a oferta de cursos e programas de educação superior no País.

Optamos pela abordagem qualitativa que "parte do fundamento de que há uma relação dinâmica entre o mundo real e o sujeito, uma interdependência viva entre o sujeito e o objeto, um vínculo indissociável entre o mundo objetivo e a subjetividade do sujeito." (CHIZZOTTI, 2000, p. 79). Nessa abordagem, o conhecimento não se faz apenas com a "junção" de dados, pois o pesquisador também participa do processo com as interpretações que faz e dos significados que atribui.

Por uma questão de delimitação da pesquisa, decidimos investigar a mediação didático-pedagógica, objeto de nossa análise, em uma disciplina do curso de Pedagogia de cada IES.

No estudo teórico, buscamos aprofundar nossos conhecimentos acerca da mediação didático-pedagógica na perspectiva históricocultural. Baseamo-nos, principalmente, nas obras de Vigotski³, Luria, Leontiev e também em autores contemporâneos que se dedicam ao estudo dessa abordagem, como Peixoto, Sforni, Moll e outros.

O estudo documental incluiu a análise de documentos, tais como: Referenciais de Qualidade para a Educação a Distância, Diretrizes Curriculares Nacionais do curso de Pedagogia, o projeto pedagógico dos cursos, planos de ensino das disciplinas pesquisadas. Também incluiu a análise do material didático utilizado: materiais de multimídia, os livros didáticos e/ou guia das disciplinas, informações colhidas nos sites das IES e materiais publicados no AVA. Este estudo visou a explicitar dados importantes, tais como: as características desses documentos, a intencionalidade destes, se interferem ou não na organização da atuação docente, como também verificar se há coerência ou conexão entre eles e o trabalho realizado pelo professor, tendo como foco a mediação didático-pedagógica.

No estudo de campo, realizamos entrevistas por pautas que, segundo

3 Nas obras pesquisadas encontramos este nome escrito de várias formas: Vigotski, Vygotsky, Vigotskii. Adotamos a forma Vigotski e conservamos a forma original adotada pelos autores nas citações diretas. 
Gil (1994), são guiadas por pontos de interesse explorados ao longo da entrevista. Há certa estruturação, mas com poucas perguntas diretas, deixando o entrevistado falar livremente. Foram entrevistados oito professores que atuam em duas disciplinas selecionadas, sendo uma de cada IES. O objetivo das entrevistas foi analisar como esses professores organizam as atividades de ensino, considerando o contexto das IES, o AVA, o material impresso e outras mídias utilizadas por eles. Para a análise dos dados, com a intenção de alcançarmos o máximo de amplitude para poder descrever, explicar e compreender tal organização utilizamos a técnica da triangulação das três diferentes fontes pesquisadas, cujo objetivo básico é descrito por Triviños (2008, p. 138):

[...] abranger a máxima amplitude na descrição, explicação e compreensão do foco em estudo. Parte de princípios que sustentam que é impossível conceber a existência isolada de um fenômeno social, sem raízes históricas, sem significações culturais e sem vinculações estreitas e essenciais com a macro realidade social.

A formação de pedagogos na modalidade EaD, na atualidade, não é um fato isolado, mas está associado à macrorrealidade social que envolve uma série de fatores. Porém, a mediação se encontra no centro de um processo que visa à aprendizagem e ao desenvolvimento do indivíduo.

\section{A mediação}

O conceito de mediação faz parte dos pressupostos vigotskianos aborda a relação indireta do homem com o mundo. O homem iniciou seu desenvolvimento interagindo com a natureza, com o ambiente de forma direta. Foi assim que Vigotski, conforme nos explica Moll (1996), detevese a pesquisar de que forma as pessoas agiam auxiliadas por instrumentos simbólicos e materiais. Como organizavam a memorização consciente, direcionavam a atenção, regulavam a conduta? Na realidade, ao longo de nossas vidas, aprendemos muitas coisas de forma direta. Oliveira (2004) exemplifica essa situação da seguinte forma: um bebê, por exemplo, ao aproximar a mão à chama de uma vela e a retira rapidamente ao sentir dor, estabelece uma relação direta. Em outro momento, ele poderá apenas retirar a mão ao sentir o calor, pois a experiência anterior está em sua 
memória, ou seja, está mediada pela lembrança de um fato já ocorrido. Essa relação pode ser mediada por outra pessoa que lhe diga que ele pode se queimar caso aproxime sua mão da chama. Sendo assim, a mediação:

[...] em termos genéricos, é o processo de intervenção de um elemento intermediário numa relação; a relação deixa, então, de ser direta e passa a ser mediada por esse elemento. [...] Vygotsky trabalha, então com a noção de que a relação do homem com o mundo não é um relação direta, mas, fundamentalmente, uma relação mediada. As funções psicológicas superiores apresentam uma estrutura tal que entre o homem e o mundo real existem mediadores, ferramentas auxiliares da atividade humana. (OLIVEIRA 2004, p. 26-27)

Esse conceito de "ferramentas auxiliares da atividade humana", também denominadas de "ferramentas psicológicas", segundo Sforni (2008, p. 497) foi criado por Vigotski para que ele pudesse mostrar que "a forma e conteúdo do pensamento possível ao homem não está em cada sujeito particular, mas nos instrumentos produzidos e disponíveis ao homem ao longo da história." Conforme dissemos anteriormente, esses "instrumentos" podem ser materiais ou simbólicos (signos) e que a apropriação gradativa do sistema de signos, dessa cultura que está fora do homem, vai constituindo o seu pensamento.

A ênfase dada por Vigotski às "ferramentas psicológicas" significa que ele valoriza o papel da interação social, pois somente interagindo é possível a apropriação dessas ferramentas. Sforni (2008) comenta sobre esse aspecto em seu artigo, como descrito no trecho a seguir:

[...] às interações sociais é dado lugar de destaque na escola de Vygotsky, mas o seu valor no contexto escolar não está restrito à relação sujeito-sujeito, mas no objeto que se presentifica nessa relação - o conhecimento. Em outras palavras, é somente na relação entre sujeito-conhecimento-sujeito que a mediação se torna um conceito fundamental ao desenvolvimento humano. (SFORNI, 2008, p. 497)

No entanto, observamos nesse comentário da autora dois aspectos que consideramos de grande importância, que são: o fato de não podermos reduzir o conceito de mediação somente às interações sociais, no sentido de relação entre sujeitos; a outra questão é acerca do papel da escola e 
do professor, ou seja, auxiliar os alunos a adquirirem o conhecimento científico, que é o objeto que se coloca nessa relação. Quando existe o auxílio de um adulto para ensinar algo, ele está, nesse momento, exercendo uma "função mediadora".

$\mathrm{Na}$ abordagem histórico-cultural, os instrumentos construídos socialmente possuem um papel fundamental no desenvolvimento do ser humano. De acordo com Oliveira (2004) e Peixoto (2011), Vigotski classifica-os da seguinte maneira:

- instrumentos/artefatos físicos ou as ferramentas. Esses instrumentos são orientados externamente, voltados para fora em relação ao sujeito que os utiliza e são dirigidos para a transformação dos objetos;

- instrumentos psicológicos ou signos (linguagem) que agem no campo psicológico, no comportamento do indivíduo. Eles realizam a mediação da atividade intelectual, auxiliam no desenvolvimento das funções psíquicas superiores. Esses instrumentos são orientados internamente, ou seja, voltados para dentro em relação ao sujeito que os utiliza.

Deve-se observar, portanto, que essa classificação é apenas uma forma de identificarmos duas naturezas diferentes de instrumentos, o que não quer dizer que as ações que os envolvam não possam ocorrer concomitantemente. Um computador, ou um livro, por exemplo, são objetos físicos orientados externamente ao sujeito, mas a linguagem presente neles (signos) são ferramentas psicológicas orientadas internamente ao sujeito.

A esse respeito, Peixoto (2011) chama nossa atenção quanto aos instrumentos utilizados na educação que têm o papel de ensinar os saberes científicos aos estudantes de forma sistematizada. Esclarece que esses não se reduzem a objetos, que têm apenas uma dimensão material, mas incluem os instrumentos psicológicos, que permitem ao homem orientar e controlar o seu pensamento. Afirma que Vigotski

[...] insiste no papel fundamental dos instrumentos construídos socialmente para o desenvolvimento humano e para a educação. [...] é preciso demarcar a distinção entre as dimensões material e simbólica do artefato, sobretudo para alertar que o artefato não se reduz ao objeto técnico ou à máquina. Ao mesmo tempo, os instrumentos psicológicos destacam-se na função de permitir ao homem o controle e a orientação de seu próprio comportamento. 
Ou seja, o signo é considerado como uma classe de artefatos fundamental ao estabelecimento das funções psíquicas superiores. (PEIXOTO, 2011, p. 98-99)

Podemos classificar os artefatos em instrumentos que possuem uma dimensão simbólica e instrumentos que possuem uma dimensão material, sendo que os primeiros são essenciais ao desenvolvimento das funções psíquicas superiores. Sendo assim, a mediação ocorre em nível externo, por intermédio dos instrumentos materiais, e em nível interno, por intermédio dos signos, pois:

Tais processos de comunicação e as funções psíquicas superiores envolvidas nesses processos, se efetivam primeiramente na atividade externa (interpessoal) que, em seguida, é internalizada pela atividade individual, regulada pela consciência. No processo de internalização da atividade há a mediação da linguagem, em que os signos adquirem significado e sentido. (VIGOTSKI, 1984 apud LIBÂNEO, 2004, p. 7)

Os signos considerados por Vigotski como instrumentos psicológicos, na medida em vão sendo internalizados e regulados pela consciência, auxiliam no desenvolvimento das funções psíquicas superiores, cujo grau de complexidade é aumentado ao longo do desenvolvimento do indivíduo. A criança aprende as primeiras palavras e os seus significados; passa a utilizá-las, constrói as primeiras frases; vai adquirindo também o significado dos gestos, das expressões, das artes etc. Ao mesmo tempo em que ela vai adquirindo o conhecimento dos signos, ou seja, internalizando os significados, ela também vai adquirindo o conhecimento dos materiais que fazem parte do seu ambiente sócio-histórico. Por exemplo, a criança reconhece uma colher (instrumento material que age externamente ao sujeito), já aprendeu sobre o uso que as pessoas fazem desse objeto e passa a utilizá-la também para se alimentar. Ela aprende a manejar a colher tanto pela observação direta, como pela mediação do outro mais experiente, que a ensina a utilizar esse talher. Com o passar do tempo, ela deverá aprender a manejar outros instrumentos mais sofisticados, que fazem parte do contexto histórico-cultural onde ela vive. No entanto, para que todo esse processo se efetive, a ação do outro por meio da interação social, é essencial, como podemos observar também nas palavras de 
Palangana, Galuch e Sforni (2002, p. 113): “Se ao nascer o sujeito for isolado do convívio com seus pares, as funções psíquicas, caracteristicamente humanas - como o raciocínio, a percepção, a memória, as emoções, dentre outras tantas - não se desenvolvem." As funções psíquicas superiores são mecanismos psicológicos, complexos e inerentes aos seres humanos. Oliveira (2004) explica que o termo "superior" serve para diferenciar de ações consideradas "elementares", tais como a busca de um bebê recémnascido pelo seio da mãe, de ações mais complexas elaboradas pelo pensamento, quando, por exemplo, lemos um livro.

Nessa busca incessante para interagir com o seu semelhante, o homem faz uso de artefatos materiais e artefatos psicológicos, que podem ser chamados também de signos e instrumentos culturais. Os signos podem ser compreendidos como todo o tipo de linguagem utilizada pelo homem na sociedade, lembrando sempre que essa linguagem pode ser verbal ou não. Os artefatos materiais compõem todo tipo de instrumento tangível, criado pelo homem. A título de exemplo, podemos citar o livro: ao mesmo tempo em que ele é um instrumento (um artefato material), ele também é um instrumento psicológico, ou seja, que contém linguagem, cujos textos só poderão ser comunicados ao nosso pensamento se os lermos e, mesmo assim, nossa condição intelectual já alcançada, deverá permitir o entendimento dessa leitura.

Assim, a categoria mediação tem um papel central na teoria vigotskiana e é fundamental no desenvolvimento do indivíduo. Como foi dito neste texto, o conceito de atividade surgiu na filosofia marxista como expressão maior do trabalho, da atividade prática que levou o homem a transformar a natureza e a se transformar. O homem não nasce pronto e para se humanizar, é preciso que ele se aproprie das aquisições históricas da humanidade. No entanto, para adquirir conhecimento, é necessário que ele interaja com o seu semelhante que o auxilia nesse processo de humanização, ou seja, as interações sociais possibilitam a apropriação da cultura e, consequentemente, o desenvolvimento da mente humana. Esse desenvolvimento ocorre quando há a mediação da linguagem, a partir do momento em que os signos passam a ter significado e sentido em nível intrapessoal ou intrapsíquico. 


\section{Aprendizagem e desenvolvimento humanos}

Ao abordar o desenvolvimento humano, precisamos diferenciar o desenvolvimento filogenético, do desenvolvimento ontogenético. Filogenético se refere ao desenvolvimento da espécie humana, a história da humanidade, mas também em seu aspecto cultural, como, por exemplo, como a espécie humana produziu e se apropriou da escrita. Mas se nos detivermos a pesquisar como a criança se apropria da escrita, estaremos realizando um estudo ontogenético. Nos parágrafos seguintes, vamos nos ater mais a esse segundo, por estar relacionado ao foco do presente estudo.

Vigotskii, Luria e Leontiev (2006) afirmavam que nenhum professor poderia ignorar o fato de que uma criança já chega à escola com certo desenvolvimento, como é possível verificar nesta afirmativa: “[...] a aprendizagem escolar nunca começa no vácuo, mas é precedida sempre de uma etapa perfeitamente definida de desenvolvimento, alcançada pela criança antes de entrar para a escola." (p. 110). Ela interage, aprende a falar, pergunta para os adultos sobre as mais diversas coisas e assuntos, recebe respostas e é assim que a aprendizagem e o desenvolvimento iniciam para a criança desde o seu nascimento.

Outra questão importante levantada por Vigoskii, Luria e Leontiev (2006) é que a capacidade potencial da aprendizagem infantil está relacionada aos níveis de desenvolvimento já alcançados pela criança. “A diferença entre o nível das tarefas realizáveis com o auxílio dos adultos e o nível das tarefas que podem desenvolver-se com uma atividade independente, define a área de desenvolvimento potencial da criança" (p.112).

Devido às diversas traduções das obras dos autores russos relacionadas ao foco do presente estudo, em que encontramos também traduções de traduções, existem termos diferentes que foram utilizados para explicar os mesmos conceitos. Ainda hoje, grupos de estudiosos da teoria histórico-cultural, do Brasil e também de outros países, divergem quanto ao emprego de determinados termos utilizados por tradutores. Prestes (2010) desenvolveu uma pesquisa de doutorado no Programa de Pós-Graduação em Educação da Universidade de Brasília (UnB) sobre as atividades de tradução das obras de Vigotski. Segundo ela, os 
equívocos de tradução de certos conceitos influenciaram na compreensão do pensamento desse autor. Conforme está relatado na introdução do seu trabalho, por ter morado desde os sete anos na Rússia, vivido e estudado lá até a vida adulta, Prestes (2010) se tornou conhecedora da língua.

Em relação aos níveis de desenvolvimento, citados anteriormente, diversos autores se referiram a eles de forma diferente. Segundo Oliveira (2004), Vigotski estabelece dois níveis de desenvolvimento:

1 NDR (nível de desenvolvimento real) - é o nível de desenvolvimento em que as crianças podem realizar atividades de forma independente; 2 NDP (nível de desenvolvimento potencial) - é definido pela capacidade que a criança possui de realizar tarefas com o auxílio de pessoas mais velhas ou de colegas mais experientes.

Também podemos encontrar autores que se referem a esses níveis como: "nível de desenvolvimento atual e nível de desenvolvimento possível". Porém, pensamos que mais importante do que a nomenclatura utilizada por tradutores é a interpretação equivocada que possa mudar o sentido do pensamento do autor. Para Prestes (2010), essa definição de NDP parece estranha ao pensamento de Vigotski, pois em todos os trabalhos que se referiram à Zona de Desenvolvimento Iminente (ZDI) a que ela teve acesso e que ainda estavam no idioma russo, em nenhum, Vigotski faz menção a um NDP. Segundo ela, o autor “[...] entende que nada está pré-determinado na criança, há muitos outros aspectos envolvidos para que os processos internos sejam despertados [...]. O que existe é um campo de possibilidades para o desenvolvimento [...]" (PRESTES, 2010, p. 174). A palavra que significava "possível" foi entendida pelos tradutores como "potencial", mudando o sentido empregado pelo autor, como podemos observar na citação a seguir, utilizada por Oliveira (2004) para definir Zona de Desenvolvimento Proximal (ZDP):

A distância entre o nível de desenvolvimento real, que se costuma determinar através da solução independente de problemas, e o nível de desenvolvimento potencial, determinado através da solução de problemas sob a orientação de um adulto ou em colaboração com companheiros mais capazes. (VIGOTSKI, 1988 apud OLIVEIRA, 2004, p. 60) 
É importante salientar, portanto, que Oliveira fez uso de obras já traduzidas. Em relação à definição de ZDP empregada por Oliveira (2004), também foram encontradas diferenças em relação às observações de Prestes (2010), que chama atenção mais uma vez para a mudança na nomenclatura empregada. Segundo ela, mudou o sentido empregado por Vigotski. Vejamos as diferenças entre Zona de Desenvolvimento Proximal (ZDP), utilizada por Oliveira (2004), Zona de Desenvolvimento Imediato (ZDI), utilizada pelo tradutor Paulo Bezerra, na obra Vigotski (2010) e a de Prestes. Para Prestes (2010), tanto a palavra "proximal" utilizada por Oliveira, quanto a palavra "imediato", utilizada pelo tradutor Paulo Bezerra, não traduzem o real pensamento de Vigotski quanto a essa zona de desenvolvimento, pois não revelam o real significado que ele dá à instrução: "Vigotski não diz que a instrução é garantia de desenvolvimento, mas que ela, ao ser realizada em uma ação colaborativa, seja do adulto ou entre pares, cria possibilidade para o desenvolvimento." (PRESTES, 2010, p. 168). Segundo ela, a palavra "iminente" é mais adequada em relação ao que Vigotski quis dizer no idioma russo, pois essa zona de desenvolvimento tem a ver com funções que ainda estão em estado embrionário, podendo ou não se desenvolver, sendo assim, a tradução mais fiel no idioma russo, seria Zona de Desenvolvimento Iminente (ZDI).

Tomando como base essas breves explicações, para a nossa pesquisa, vamos adotar a seguinte nomenclatura, lembrando que, para as citações utilizadas, vamos conservar a nomenclatura utilizada pelos autores:

- ZDI: Zona de Desenvolvimento Iminente;

- NDR: Nível de Desenvolvimento Real.

Para Prestes (2010), não se pode reduzir as atividades que ocorrem na ZDI apenas às atividades escolares, pois, para Vigotski, essa situação pode ocorrer em qualquer ambiente social, sob quaisquer circunstâncias, ou seja, em casa, na casa de amigos, no parque, na igreja, entre outros locais.

É comum quando convivemos com crianças pequenas, sejam elas nossos filhos, sobrinhos, netos ou amigos, observarmos o desenvolvimento 
delas, seus avanços e sucessos nas ações que desempenham sozinhas, que não necessitam mais da ajuda de outra pessoa. Muitas vezes nos deparamos comparando-as com outras crianças de idade semelhante. Ao fazermos isso, estamos nos referindo ao que Vigostki denominou de NDR, ou seja, são etapas que a criança já alcançou, já consolidou em seu desenvolvimento.

É possível observarmos também que, em determinadas situações, as crianças são capazes de realizar tarefas ao receberem instruções de alguém mais velho ou mais experiente. São tarefas que, a princípio, não conseguiriam realizar sem essas instruções. O que Vigotski demonstra nesse fato é algo fundamental em sua teoria, pois representa a alteração no desempenho de uma pessoa pela interferência de outra. Ele atribui extrema importância à interação social no processo de construção das funções psicológicas superiores.

A criança que está realizando uma atividade poderá alcançar o NDR para essa tarefa em bem menos tempo do que se não tivesse recebido o auxílio de alguém. Mas não podemos esquecer que "não é qualquer indivíduo que pode, a partir da ajuda de outro, realizar qualquer tarefa, isto é, a capacidade de se beneficiar da colaboração de outra pessoa vai ocorrer num certo nível de desenvolvimento, mas não antes." (OLIVEIRA, 2004, p. 59, grifo nosso). O que precisamos observar é que a tarefa deve estar de acordo com o desenvolvimento da pessoa. Para exemplificarmos essa questão, podemos dizer que não seria prudente querermos ensinar uma criança de cinco anos a jogar xadrez, pois essa é uma tarefa que não estaria de acordo com o nível de desenvolvimento dela. Esse jogo exige uma série de competências e habilidades que só com o passar do tempo será desenvolvida e adquirida, mas isso não impossibilita o ensino de alguns conhecimentos básicos acerca do jogo.

O trabalho do professor, sua atenção, seu planejamento deve estar voltado para a ZDI dos alunos. Isso significa considerar o NDR dos alunos para, a partir daí, ir além. "[...] o principal papel da escolarização é criar contextos sociais (zonas de desenvolvimento proximal) para o domínio e o manejo consciente dos usos desses instrumentos culturais." (MOLL, 1996, p. 13). Nesse contexto, a linguagem é entendida como 
instrumento psicológico cultual de imenso poder e, na sociedade, os signos possuem significados que são compartilhados por seus membros. Segundo Palangana, Galuch e Sforni (2002, p. 118):

As noções adquiridas socialmente, sobretudo por meio da linguagem, não resultam apenas numa acumulação quantitativa de sistemas de associações que refletem a ação no mundo exterior. Essas aquisições modificam qualitativamente as formas de atividade cognitiva, favorecendo o desenvolvimento de múltiplas capacidades.

As capacidades desenvolvidas por meio da ampliação do vocabulário na língua materna permitem ao homem realizar, gradativamente, tarefas mais complexas. Por exemplo, primeiro se aprende a falar para depois, aprender a ler e escrever. Na medida em que se adquirem conhecimentos, amplia-se a possibilidade de realização de leituras com conteúdos mais complexos. Devemos considerar, contudo, que, no caso de um livro (objeto cultural), mesmo que o seu conteúdo contenha informações compatíveis com o nível de desenvolvimento intelectual de uma pessoa, se ele estiver escrito em uma língua diferente e incompreensível para ela, será necessário o auxílio de um intérprete ou tradutor.

Como foi possível observar, o desenvolvimento dos processos psicointelectuais superiores da criança se referem à aprendizagem, pois ela:

[...] estimula, ativa na criança um grupo de processos internos de desenvolvimento no âmbito das inter-relações com outros, que, na continuação são absorvidos pelo curso interior de desenvolvimento e se convertem em aquisições internas da criança. Considerada deste ponto de vista, a aprendizagem não é, em si mesma, desenvolvimento, mas uma correta organização da aprendizagem da criança conduz ao desenvolvimento mental, ativa todo um grupo de processos de desenvolvimento, e esta ativação não poderia produzir-se sem a aprendizagem. (VIGOTSKII; LURIA; LEONTIEV, 2006, p. 115)

As palavras de Vigotskii, Luria e Leontiev (2006) e Leontiev (1978) nos remetem a uma aprendizagem humana incessante, que vai se ampliando cada vez mais, ou seja, há um movimento "aprendente" constante, que modifica o nível de desenvolvimento e altera a ZDI ao longo da vida. Existe todo um passado vivenciado e também um futuro que a pessoa vê diante de si. Em relação à aprendizagem dos adultos, Vigotski, Lúria e Leontiev 
(2006, p.115) comentam que eles: “[...] dispõem de uma grande capacidade de aprendizagem [...]. Mas até agora não se descreveu adequadamente o que diferencia, de forma substancial, a aprendizagem do adulto da aprendizagem da criança." Consideramos, então, nesse estudo, que esse movimento aprendente nunca cessa no decurso da vida, salvo em condições adversas, tais como incapacidades causadas por doenças ou fatalidades, que impeçam a pessoa de seguir um curso de aprendizagem incessante. Apesar de esses autores reconhecerem a capacidade de aprendizagem dos adultos, uma vez que eles acumularam experiências de aprendizagem ao longo da vida, porém, os estudos psicológicos, didáticos, voltaram-se muito mais para a aprendizagem da criança.

Há que se observar, também, a qual aprendizagem estamos nos referindo, pois existem relações diferentes da aprendizagem com o processo de desenvolvimento. Para explicar melhor, vamos usar o seguinte exemplo: se considerarmos a habilidade que alguém possui de digitar com rapidez um teclado de computador, esse tipo de habilidade não altera, de forma efetiva, as características psicointelectuais dessa pessoa. “Uma aprendizagem deste gênero aproveita um desenvolvimento já elaborado e completo, e justamente por isso, contribui muito pouco para o desenvolvimento geral." (VIGOTSKII; LURIA; LEONTIEV 2006, p. 116). Existem aprendizagens que envolvem processos mentais mais complexos e outras que envolvem processos mentais mais simples. A título de exemplo, o que ocorre na alfabetização é muito diferente: "Algumas pesquisas demonstram que este processo ativa uma fase de desenvolvimento dos processos psicointelectuais inteiramente nova e muito complexa." (VIGOTSKII; LURIA; LEONTIEV, 2006, p. 116).

Retomando o objeto da presente pesquisa, que considera a aprendizagem de um adulto que frequenta um curso superior de Pedagogia, na modalidade EaD, observamos que as IES devem ter como foco, em relação à aprendizagem dos alunos, a ativação dos seus processos psicointelectuais. É claro que, em se tratando de pessoas adultas e com certo grau de escolarização adquirido, as atividades, como dissemos, devem estar compatíveis com o seu nível de desenvolvimento. Palangana, Galuch e Sforni (2002, p. 119) esclarecem que: 
O que deve desafiar e ocupar os professores não são as atividades nas quais os alunos desempenham sozinhos com declarada competência, pois essas pouco ou nada acrescentam ao desenvolvimento. Cabe a eles, isto sim, preocuparem-se e ocuparem-se com os conteúdos, as atividades, nos quais o desempenho do aluno depende da mediação, de ensino.

Se o aluno não está necessitando da mediação do professor, é porque as atividades propostas estão no NDR do aluno e, por isso, pouco ou nada acrescentam em seu desenvolvimento. Segundo as autoras, um ensino só se justifica quando desenvolve nos educandos novas capacidades, sobretudo as de generalização e abstração; quando os leva a aprender novos conceitos; quando promove a reflexão, a análise, a síntese; quando os leva a se expressarem e a atribuírem significados com vocabulário próprio e coerente; quando eles aprendem a lidar com informações interpretando-as. A forma como os conteúdos são trabalhados em uma instituição revela a qualidade do ensino que ela oferece (PALANGANA; GALUCH; SFORNI, 2002).

\section{As atividades de ensino na EAD}

As atividades organizadas pelos docentes na EaD envolvem uma organização mais complexa do que costuma ser o ensino na modalidade presencial. Para o alcance dos objetivos pretendidos, segundo a teoria histórico-cultural, o processo ensino-aprendizagem não pode prescindir da mediação didática docente. Os modelos de EaD estão pautados em uma organização em que a aula não assume o papel de atividade principal do professor. Vigotski já considerava que a aula é apenas uma parte da atuação do professor, que orienta, organiza o ensino, elege ações e estabelece instrumentos.

O momento histórico-social atual mudou a organização e os métodos de ensino. As tecnologias que o homem criou, dentro dessa lógica dialética, mudaram também o homem, que busca outras formas de organização que dependem das tecnologias. É por esse motivo que, não só a didática, mas as organizações e os métodos de ensino devem ser também foco de pesquisas na área educacional. 


\section{Mediação didática: a organização do trabalho docente, os Ambientes Virtuais de Aprendizagem (AVA), os instrumentos e as mídias}

A análise dos dados dos documentos e do desenho didático das IES, permitiu-nos constatar que os docentes da modalidade EaD atuam dentro de limites pré-estabelecidos pelas equipes administrativas, pedagógicas e multidisciplinares das instituições e que a docência se encontra diluída entre vários atores do processo. A organização do trabalho docente está subordinada ao modelo pedagógico adotado pelas IES, explicitados em seus Projetos Pedagógicos (PP). Segundo Mattar (2012), os PP não se constituem em atividades totalmente neutras, mas sim, pressupõem paradigmas, matrizes culturais e históricas.

Os estudos bibliográfico e documental mostraram claramente que, para a abordagem histórico-cultural, a interação social é muito importante no processo ensino-aprendizagem e, por isso, o AVA tem um papel importante a cumprir, ao possibilitarem a comunicação ampla entre os atores desse processo. As atividades de ensino devem ser mediadas pelos professores e/ou tutores e os materiais didáticos impressos, entre outras mídias utilizadas pelas IES, não podem realizar o trabalho de mediação sem a intervenção dos docentes, ao longo do processo ensino-aprendizagem, por isso, se faz necessária a análise dos fatores que interferem na atuação docente.

Segundo Mattar (2011), mídias são meios utilizados para comunicar, instruir, entre outras finalidades. Podemos considerar como mídia: o material impresso, CD, DVD, televisão, teleconferência, webconferências, rádio etc. Como podemos observar, essas mídias podem permitir a intercomunicação ou não, podem ser síncronas ou assíncronas. As que não permitem a intercomunicação privilegiam a comunicação informacional, sem feedback, como por exemplo, os livros ou DVD. As síncronas permitem intercomunicação em tempo real; é o caso das videoconferências, webconferências, entre outras. As assíncronas permitem a intercomunicação, mas não em tempo real, como, por exemplo, a ferramenta fórum e o $e$-mail, bastante utilizados nos Ambientes Virtuais 
de Aprendizagem. As mídias utilizadas pelas IES pesquisadas são:

- a IES "A" utiliza os materiais didáticos em mídia impressa (livros didáticos), oficinas gravadas e disponibilizadas na Web; - a IES “B” utiliza os materiais impressos, que são os guias das disciplinas elaborados pelos professores, um DVD contendo uma aula gravada.

Ambas utilizam o AVA como ambiente midiático e, como mídia principal para estudo e consulta, os materiais impressos em forma de livros ou guias. A IES “ A" utiliza um AVA próprio, que está em constante aprimoramento. A "central de mensagens" e a "caixa de comentários" das questões abertas são as ferramentas interativas mais utilizadas para a comunicação entre professores e alunos. O fórum, como ferramenta interativa e assíncrona, possui um peso grande na avaliação dos alunos, fazendo com que eles se empenhem em participar da atividade; contudo, a avaliação não pode ser considerada como um elemento motivador para a participação do aluno em uma atividade. Observamos também a existência de ferramentas que possibilitam maior interação, porém, não estão sendo aproveitadas. Na IES “B”, o AVA Moodle é um potente gerador de salas de aulas capazes de contemplar mediação docente e aprendizagem participativa, colaborativa. Suas salas de aula "virtuais" são capazes de potencializar o ofício do professor e o trabalho dos cursistas (SILVA, 2011). Entretanto, são pouco utilizadas, como também o Café Virtual e os Fóruns de Dúvidas.

Para Peixoto (2011), os materiais didáticos possuem a dimensão material (instrumentos físicos), como também a dimensão simbólica (instrumentos psicológicos). Eles "[...] permitem o estabelecimento das relações do sujeito com o meio, consigo mesmo e com os outros, podemos compreender como, no ato instrumental, o sujeito faz uso do instrumento material, mas também de si mesmo." (PEIXOTO, 2011, p. 100). Porém, precisamos considerar que, nesse ato instrumental, tomando como base as análises realizadas sobre a organização dos projetos pedagógicos das IES, o professor atua dentro de certos limites pré-estabelecidos e o aluno segue a organização do professor. 
Em relação ao apoio técnico e de formação para lidar com as tecnologias, os professores das duas IES alegam que receberam, mas, mesmo assim, observamos certos procedimentos metodológicos inadequados. Segundo Peixoto (2011, p. 104), os instrumentos podem ser "desvirtuados" da sua funcionalidade original: "fatores de ordem técnica, cultural, econômica e política podem desencadear formas ou esquemas de uso que fogem dessas funções originalmente concebidas. [...]. Assim, os instrumentos podem ser utilizados apenas parcialmente da forma como foram concebidos." Contudo, devemos considerar que a maioria dos professores e tutores entrevistados de ambas as IES relatou que está vivenciando a sua primeira experiência em EaD.

Em relação às práticas pedagógicas mediadas pelas Tecnologias da Informação e Comunicação (TICs), Peixoto (2011, p. 109) afirma que: “Consideradas à luz do conceito de atividade mediada, as TIC precisam ser tomadas em sua funcionalidade e materialidade técnica e, neste sentido, como meios para o alcance das finalidades diversas." Partindo das palavras da autora, podemos afirmar que o diálogo entre equipe técnica e pedagógica se torna essencial nessa modalidade de ensino, para que as ferramentas possam receber os ajustes necessários de maneira a atenderem aos objetivos pedagógicos, o que nem sempre ocorre a contento.

Outra questão que nos pareceu fazer parte da cultura nessa modalidade se deve ao fato de os alunos não aproveitarem as ferramentas disponíveis para a interação social, as quais visam à apropriação dos conteúdos e ao contato com os envolvidos no processo, limitando-se a fazer as atividades que lhes são "cobradas".

\section{A análise da atuação dos professores e tutores no AVA: interação}

Pudemos constatar que os AVA, tanto da IES "A" quanto da IES “B”, apresentam ferramentas interativas e possibilidades para o professor organizar as atividades docentes; no entanto, nem todo o potencial desses ambientes foi utilizado pelos professores responsáveis pela organização das disciplinas pesquisadas. Por isso, o AVA não pode ser considerado como limitadores da atuação do professor, mesmo porque, as inovações 
tecnológicas têm caminhado passos à frente dos usuários.

A interação, considerada como fator prioritário para a teoria histórico-cultural na construção do conhecimento, não se efetiva de modo dialógico, bidirecional na organização das atividades de ensino do professor das IES pesquisadas, acarretando prejuízos na mediação realizada pelos tutores ou professores-tutores, situação revelada pelas observações empíricas.

Na IES " $\mathrm{A}$ ", o professor-tutor assume uma quantidade de turmas e alunos que impossibilita a interação e a mediação adequadas. Mais alunos são atendidos com menos funcionários e em menos horas trabalhadas. “Eu tento mediar os fóruns das disciplinas que eu sou responsável, mas não dá para fazer com todas as turmas; são 34 turmas e é impossível fazer a mediação com todas elas." (Professora-Tutora). Nessa IES, o professor responsável também é professor-tutor e o acúmulo de funções prejudica a interação e mediação adequadas. Em relação à avaliação no AVA, a IES prioriza as questões de múltipla escolha, corrigidas automaticamente pelo sistema, diminuindo a possibilidade de interação do aluno com o professor-tutor e a oportunidade de intervenções mediadoras entre o professor e o aluno, uma vez que não há um feedback dessas correções.

A IES “B” segue o sistema UAB: o tutor a distância realiza a mediação dos conteúdos e deve seguir as determinações do professor; entretanto, não se exige que a sua formação seja em Pedagogia; o professor da disciplina não costuma entrar em contato com os alunos - ele elabora os materiais; o tutor a distância, que tem a função de corrigir todas as questões do AVA e as avaliações dos alunos, não costuma contatar o professor da disciplina no decorrer do curso, pois, quando surgem dúvidas, ele contata primeiro com a coordenação de tutoria; a coordenação de tutoria só entrará em contato com o professor da disciplina se houver necessidade; o tutor presencial contata diretamente com os alunos, mas não pode realizar a mediação de conteúdos, pois suas tarefas se restringem a questões técnicoadministrativas. Os problemas em relação à interação ficam evidenciados nessa IES pela sua estrutura de organização.

Nesse sentido, Silva (2012) chama nossa atenção em relação à utilização do termo "educação a distância", uma vez que a web 2.0 trouxe 
uma nova fase para essa modalidade de ensino, possibilitando uma “educação on-line - (EOL)". Dessa forma, "[...] perde-se a oportunidade de diferenciar a modalidade feita tradicionalmente, à base de meios unidirecionais que separam docentes e cursistas, da modalidade que cresceu com a internet e ganha mais recursos de interatividade." (SILVA, 2012, p. 96). Entretanto, não basta mudar a nomenclatura da educação e continuar praticando um ensino unidirecional, continuar adotando um desenho didático dos conteúdos e das atividades de aprendizagem que não considera e viabiliza a interação e a mediação, embora nas IES pesquisadas, não se fale em "educação on-line".

Os motivos que identificamos para a pouca interação nas IES pesquisadas são diversos; no entanto, fatores ligados à gestão dos cursos foram os mais evidenciados. Na IES " $\mathrm{A}$ ”, os principais motivos são: o pouco tempo destinado às atividades de mediação e o excessivo número de alunos atendidos. Na IES “B”, a contratação de tutores que não são considerados professores na IES pública, a natureza do vínculo estabelecido entre os tutores e a instituição, entre outros fatores, aparecem como sérios obstáculos.

\section{Considerações finais}

Os princípios educacionais defendidos por Vigotski, entre outros pesquisadores da abordagem histórico-cultural, estão muito atuais e apropriados para uma educação on-line, que, conforme Silva (2012), permite relações horizontais abertas, colaboração, coautoria, presença virtual nas interfaces. A educação, nessa perspectiva, visa à humanização do ser humano, o que só é possível por meio da apropriação da cultura acumulada historicamente. Esse processo é mediado pelos instrumentos e por outros homens, desempenhando a linguagem um papel fundamental.

Nessa perspectiva, a construção de conhecimentos só é possível por meio das interações sociais; e o papel das instituições educacionais é intervir intencionalmente no desenvolvimento do educando, independentemente de sua idade. Nesse processo, o professor atua como mediador. 
Diante da expansão da EaD, o curso de Pedagogia vem despontando como um dos mais procurados e o pedagogo é chamado a assumir seu papel no cenário educacional brasileiro. Entretanto, organizar as atividades de ensino por meio de ambientes virtuais de aprendizagem tem sido um desafio para os docentes e instituições. A web 2.0 trouxe uma nova fase para EaD, possibilitando uma educação on-line, mas essa oportunidade não tem sido bem aproveitada pelas IES pesquisadas.

A análise que realizamos sobre as concepções e os princípios que fundamentam as propostas pedagógicas dos cursos, como também ao preconizado na legislação referente à EaD e ao curso de Pedagogia, mostra incongruências entre o proposto e o realizado. A abordagem sócio-histórica, assim como a interdisciplinar, que está na base das propostas analisadas, não se sustenta em práticas em que a interação, a colaboração, o diálogo estão pouco presentes.

Com relação ao desenho didático dos cursos, não se dá prioridade à relação com o outro nas interfaces do processo educativo. A organização das atividades de ensino está submetida a determinações verticalizadas, que engessam a atuação docente, não dando a ele oportunidade de realizar a mediação didático-pedagógica de forma mais apropriada, a interagir mais com o aluno, mesmo que ele assim o deseje.

Ao se definir a EaD como uma modalidade de ensino em que a mediação didático-pedagógica nos processos de ensino e aprendizagem ocorre com a utilização das tecnologias de informação (Decreto n. 5.622/05), acredita-se que, de fato, as ferramentas hoje disponíveis, como as da web 2.0 - fórum, chat, blog, ferramentas do tipo wiki, que permitem "o estar junto on-line - colaborativo e dialógico", como nos fala Silva (2012, p. 101) -, estejam sendo utilizadas. Entretanto, a análise dos Ambientes Virtuais de Aprendizagem (AVA) colocados no cerne da $\mathrm{EaD}$, como que estabelecendo uma nova forma de presencialidade, mostraram que mesmo existindo essas ferramentas interativas, acabam sendo pouco utilizadas, não surtindo o efeito desejado para o qual foram concebidas; que os alunos se preocupam em fazer as atividades pouco interativas e que lhes são "cobradas".

Na atuação docente, observamos a fragmentação e precarização do 
trabalho, além de certa resistência a essa modalidade. Na IES pública, os professores são pesquisadores, ministram aulas nos cursos presenciais e pouco ou nenhum tempo lhes resta para a interação com os alunos. Os tutores, ao receberem uma bolsa de baixo valor da UAB, têm essa atividade como complementar, como de segunda ordem e/ ou passageira. Na IES privada, os professores atendem a um grande número de alunos e acumulam funções.

Com relação à interação, considerada como fator prioritário para a teoria histórico-cultural na construção do conhecimento, não se efetiva de modo dialógico, bidirecional na organização das atividades de ensino do professor das IES pesquisadas, acarretando prejuízos à mediação didático-pedagógica.

Esta pesquisa revelou uma parte da organização didático-pedagógica dos cursos pesquisados. Levantou aspectos que necessitam de atenção, discussão e reflexão por parte de todos os profissionais que, de alguma forma, estão envolvidos com essa modalidade de ensino. Mostrou-nos que a educação a distância no Brasil necessita de mais estudo e pesquisa para alcançarmos uma compreensão real e adequada acerca de suas características, para possibilitar a transição da EaD para o "ensino online".

Estamos cientes dos limites desta pesquisa que não nos possibilitou analisar o aluno no processo de ensino-aprendizagem, colher sua opinião acerca da mediação didático-pedagógica e dos processos de interação nos cursos que investigamos. Porém, são questões que carecem de investigações futuras no sentido de contribuírem para o processo educacional vivenciado em cursos a distância. 


\section{Referências}

BRASIL. Lei n. 9.394, 20 de dezembro de 1996. LDB - Lei de Diretrizes e Bases da Educação Nacional. 1996. Disponível em: <http:/ / bd.camara.gov.br/bd/bitstream/handle/bdcamara/2762/ldb_6ed. pdf?sequence=7>. Acesso em: 27 fev. 2013.

BRASIL. Decreto n. 5.622, de 19 de dezembro de 2005. Secretaria de Educação a Distância. Disponível em:<http:/ / www.planalto.gov.br/ ccivil_03/_Ato2004-2006/2005/Decreto/ D5622.htm> Acesso em: 28 fev. 2013.

BRASIL, Ministério da Educação. Secretaria de Educação a Distância. Referenciais de qualidade para educação superior a distância. Brasília, 2007. Disponível em: <http://portal.mec.gov.br/seed/arquivos/pdf/ legislacao/refead1.pdf>. Acesso em: 30 nov. 2012.

BRASIL. Instituto Nacional de Estudos e Pesquisas Educacionais Anísio Teixeira. Assessoria de Imprensa INEP/MEC. Brasília, 2009. Disponível em: <http://www.inep.gov.br/imprensa/noticias/censo/ superior/news09_05.htm>. Acesso em: 12 dez. 2010.

CHIZZOTTI, A. Pesquisas em ciências humanas e sociais. 4. ed. São Paulo: Cortez, 2000.

GIL, A. C. Métodos e técnicas de pesquisa social. 5. ed. São Paulo: Atlas, 1999.

LEONTIEV, A. N. Atividade, consciência e personalidade. Trad. de Sílvia Martins. 1978. Disponível em: <http:/ / www.marxists.org/>. Acesso em: 21 out. 2012.

LIBÂNEO, José Carlos. A didática e a aprendizagem do pensar e do aprender: a teoria histórico-cultural da atividade e a contribuição de 
Vasili Davydov. 2004. Disponível em: <http:/ / www.scielo.br/pdf/ rbedu/n27/n27a01.pdf >. Acesso em: 13 fev.2012.

MATTAR, J. Guia de educação a distância. São Paulo: Cengage Learning: Portal Educação, 2011.

MATTAR, J. Tutoria e interação em educação a distância. São Paulo: Cengage Learning, 2012. (Série Educação e Tecnologia).

MOLL, L. C. Vygotsky e a educação: implicações pedagógicas da psicologia sócio-histórica. Trad. Fani Tesseler. Porto Alegre: Artes Médicas, 1996.

OLIVEIRA, M. K. Vygotsky: aprendizado e desenvolvimento: um processo sócio histórico. 4. ed. São Paulo: Scipione, 2004.

PALANGANA, I. C.; GALUCH, M. T. B.; SFORNI, M. S. de F. Acerca da relação entre ensino, aprendizagem e desenvolvimento. Revista Portuguesa de Educação, Braga, Portugal, v. 15, n. 1, Universidade do Minho, p. 111-128, 2002.

PEIXOTO, J. Tecnologias e práticas pedagógicas: as TIC como instrumentos de mediação. In: LIBÂNEO, J. C.; SUANNO, M. V. R. (Orgs.). Didática e escola em uma sociedade complexa. Goiânia: CEPED, 2011. p. 97-112.

PRESTES, Z. R. Quando não é quase a mesma coisa: Análise das traduções de Lev Semionovich Vigotski no Brasil - Repercussões no campo educacional. UNB, Brasília, 2010. Disponível em: <http:/ / biblioteca.fe.unb.br/pdfs/2010-03-191048zoiaprestes.pdf>. Acesso em: 27 fev. 2013.

SILVA, M. Educação a distância (EAD) e educação on-line (EOL) nas reuniões do GT16 da Anped (2000-2010). Revista Teias, Rio de Janeiro, 
v. 13, n. 30, p. 95-118, set./dez. 2012. Disponível em: http://www. periodicos.proped.pro.br/index.php?journal=revistateias\&page= article\&op=view\&path\%5B\%5D=1362. Acesso em: 27 fev.2013.

SILVA, R. S. da. Moodle para autores e tutores. 2. ed. São Paulo: Novatec Editora, 2011.

SFORNI, M. S. de F. Aprendizagem e desenvolvimento: o papel da mediação. In: CAPELLINI, V. L. F.; MANZONI, R. M. (Orgs.). Política pública, práticas pedagógicas e ensino-aprendizagem: diferentes olhares sobre o processo educacional. Bauru: UNESP/FC/São Paulo: Cultura Acadêmica, 2008. p. 497-505.

TRIVIÑOS, A. N. S. Introdução em pesquisa em ciências sociais: a pesquisa qualitativa em educação. São Paulo: Atlas, 2008.

VIGOTSKI, L. S. A construção do pensamento e da linguagem. 2 ed. Trad. Paulo Bezerra. São Paulo: Martins Fontes, 2010.

VYGOTSKII, L. S.; LURIA, A. R.; LEONTIEV, A. N. Linguagem, desenvolvimento e aprendizagem. 10. ed. São Paulo: Ícone, 2006.

VYGOTSKY et al. Linguagem, desenvolvimento e aprendizagem. São Paulo: Ícone/Edusp, 1988.

Recebido: 01/07/2013

Aprovado: 28/09/2013 